\title{
Local and global stand-alone tests of the Météo-France snow parameterization
}

\author{
Hervé Douville \\ Météo-France/CNRM, 42 Avenue Coriolis, 31057 Toulouse Cédex, France
}

\begin{abstract}
Both observational studies and numerical experiments demonstrate the sensitivity of the atmosphere to variations in the extent and mass of snow cover. There is therefore a need for simple but realistic snow parameterizations in forecast and climate models. A new snow hydrology has recently been developed at Météo-France. This parameterization has been validated off-line against field measurements, as well as in a fully interactive numerical climate experiment. In this study, further tests were performed in stand-alone mode. The results indicate that the scheme is able to reproduce snow-cover evolution, both on local and global scales, and some directions to improve the parameterization further are suggested.
\end{abstract}

\section{INTRODUCTION}

Most general circulation models (GCMs) still show serious deficiencies in accurately representing snow cover and snow-mass distribution (Foster and others, 1996). A new one-layer snow model has been introduced in the Interactions between Soil, Biosphere and Atmosphere (ISBA) land-surface scheme (Noilhan and Planton, 1989), in order to improve the snow-cover climatology simulated by the ARPEGE (Action de Recherche Petite Échelle Grande Échelle) climate model of Météo-France. The aging process of the snowpack is considered through prognostic equations for snow density and snow albedo. Snow thermal properties depend on the density, which increases exponentially with time. Snow albedo evolves as a function of the rates of snowfall and snowmelt. The scheme computes a single-surface energy budget, but takes account of the vegetation cover when estimating surface albedo and snowmelt. Further details about parameterization may be found in Douville and others (1995a).

This simple snow model was first tested in stand-alone experiments forced by observed radiative fluxes and meteorological variables at selected instrumented sites, thereby demonstrating its ability to predict snow-depth and snow-albedo evolution over a wide range of surface conditions (Douville and others, 1995a). It was also validated within the ARPEGE climate model during a 3 year present-day climate simulation. The results of this fully interactive and global experiment have shown clearly a positive impact of the parameterization, not only on the simulated snow cover, but also in general atmospheric circulation (Douville and others, 1995b). In this study, further tests are performed with the off-line version of the ISBA land-surface scheme, both on local and global scales.

\section{LOCAL VALIDATION}

The Centre d'Étude de la Neige (CEN), which is part of the research center of Météo-France, has collected meteorological and snow measurements at a well-instrumented site for several years. This site is named Le Col de Porte, and is located at $1320 \mathrm{~m}$ a.s.l. in the northern French Alps. Continuous snow cover usually lies from late-November to the beginning of May. Deep snow is wet most of the time, but upper snow is submitted to varied conditions depending on the weather. All the input meteorological and radiative data necessary to run the ISBA land-surface scheme are observed hourly. Precipitation is measured using various rain gauges, permitting the distinction between snow and rain. Hourly observations of snow depth, surface albedo and surface temperature are also collected automatically and are used for validating the simulations.

The ISBA scheme was tested from 17 December 1988 to 6 May 1989, and from 17 December 1994 to 19 May 1995, without recalibration. For both winter seasons, the results indicate that the scheme simulates snow-cover evolution in a reasonable way, given the simplicity of the parameterization (Fig. 1). During cold periods, settling of the snowpack is reproduced, even if the fresh snow density is sometimes underestimated. During warm events, the melting rate is realistic, so that the erosion of the snow cover is well simulated. The scheme captures both the mean level and the large fluctuations of the snow albedo between successive snowfalls. The simulated surface temperature is also consistent with the observations.

Nevertheless, there are some gaps between the simulations and the field measurements. During the winter of 1988-89, the main discrepancy is an underestimation of the albedo between days 50 and 60 , which is associated with an over-estimation of the melting rate. This might be due to the neglect of the liquid water within the snowpack, which can delay the decrease of snow reflectivity and depth through nocturnal refreezing. In the same way, this approximation could explain that the rate of decrease in snow depth is slightly overestimated at the end of the winter of 1994-95. The analysis of the surface-energy budget, and the comparison with the simulations performed at the CEN with a more sophisticated multi-layer snow model, should allow the investigation of this problem in more detail. 

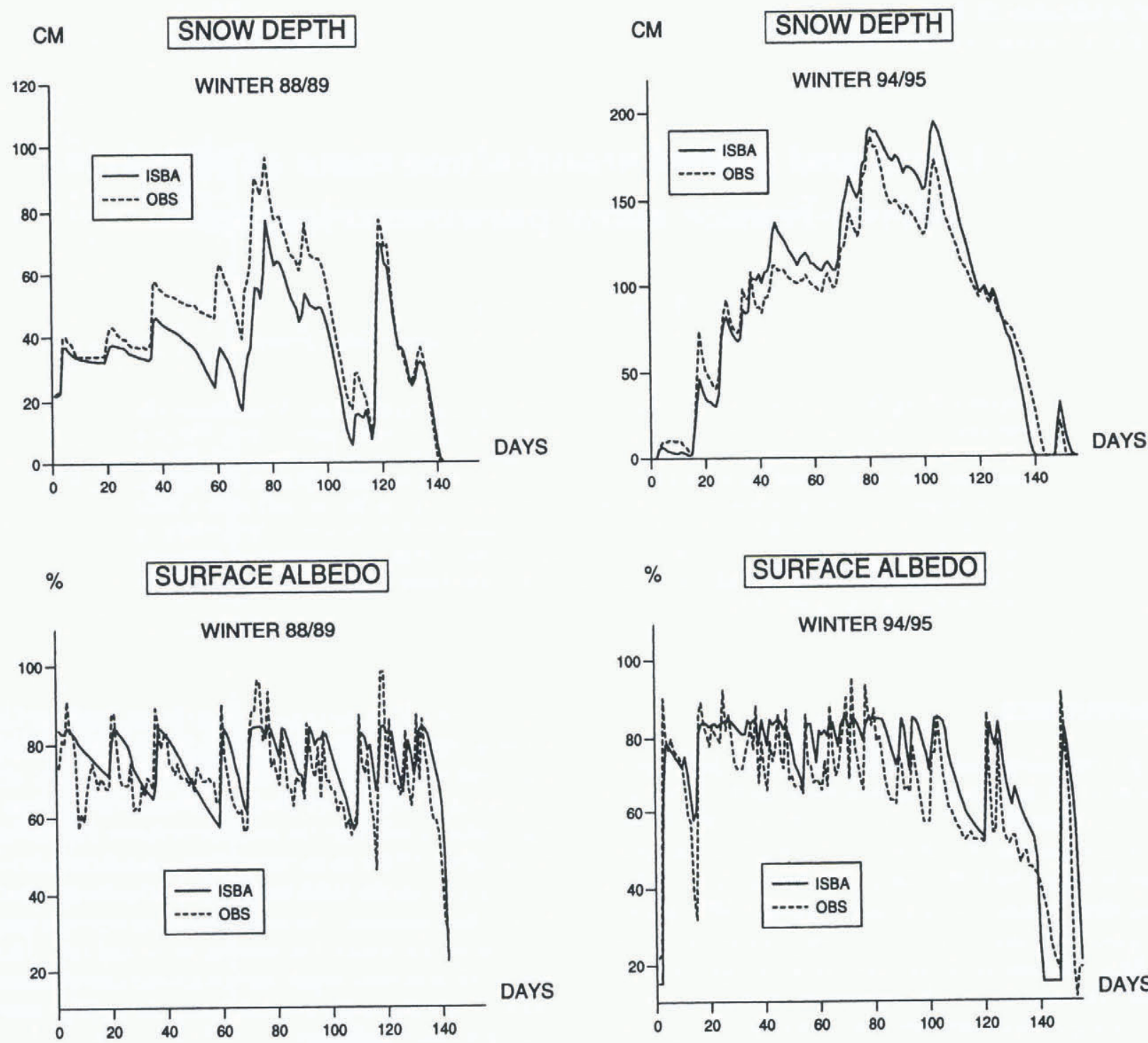

DAYS
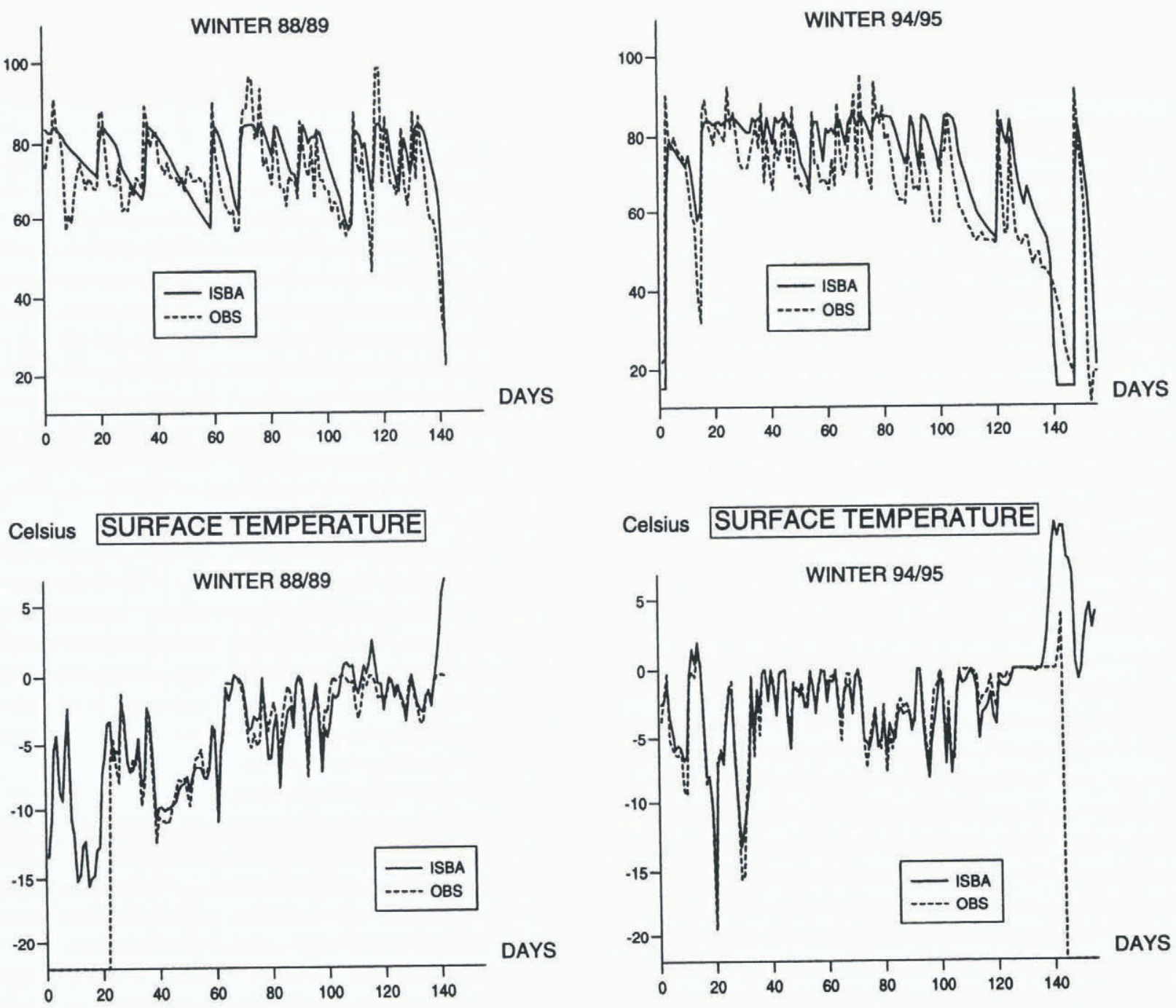

Fig. 1. Snow depth, surface albedo and surface temperature simulated and observed at Le Col de Porte in winter 1988-89 and 1994 -95 (the temperature measurements start after 22 days in 1988).

\section{GLOBAL VALIDATION}

In the framework of the Global Soil Wetness Project (GSWP), the ISBA land-surface scheme has been forced on the global scale with observed precipitation (GPCP) and radiative fluxes (ISCCP), as well as with analysed near-sur- face parameters (ECMWF) over the period 1987-88. The main objective is to produce a global soil-moisture climatology at at $1^{\circ} \times 1^{\circ}$ resolution (Dirmeyer, 1995). Another product available from this experiment is a snow-cover climatology. 
SNOW WATER EQUIV (MM) - JAN87- ISBA

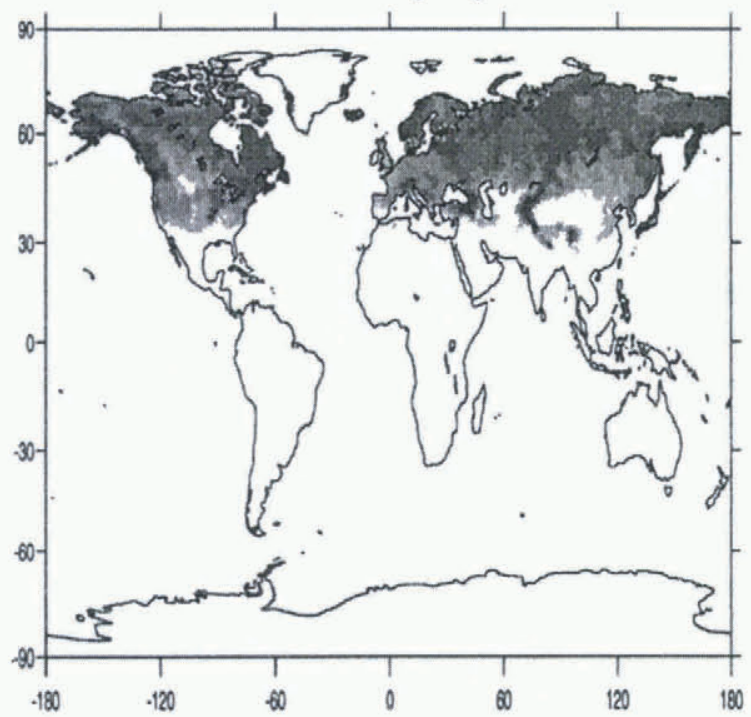

SNOWWATER EQUIV. (MM) - JAN87 - SMMR

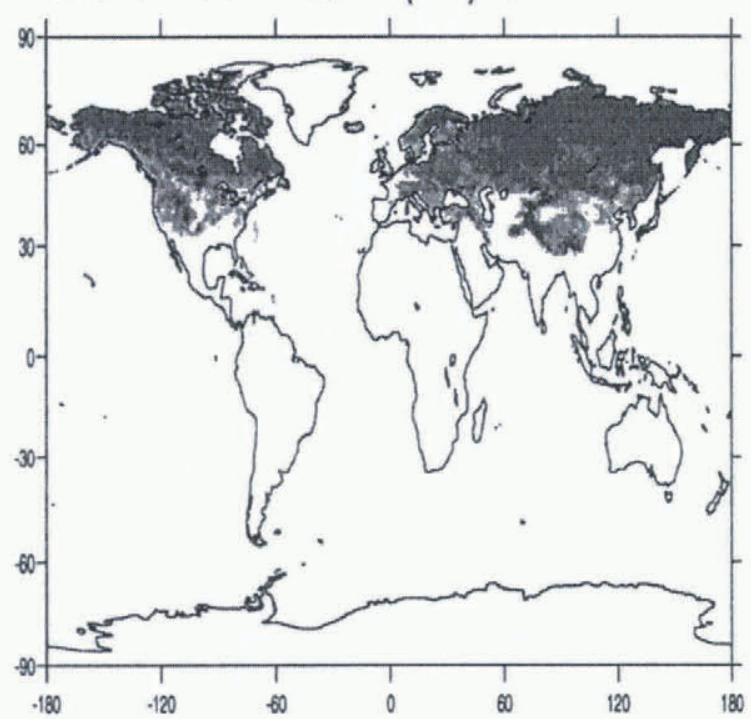

SNOW WATER EQUV (MM)-JAN-USAF

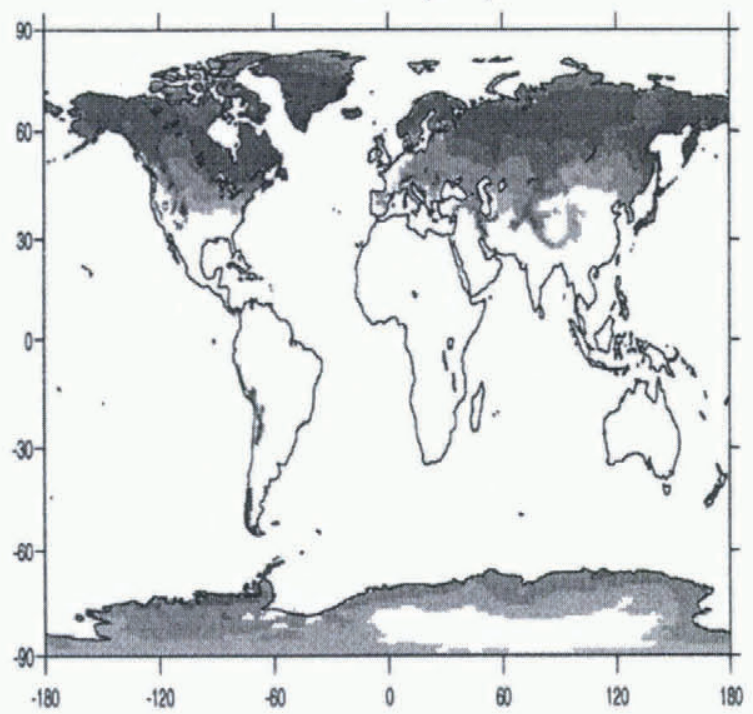

SNOW WATEREQUIV (MM) - APR87 - ISBA

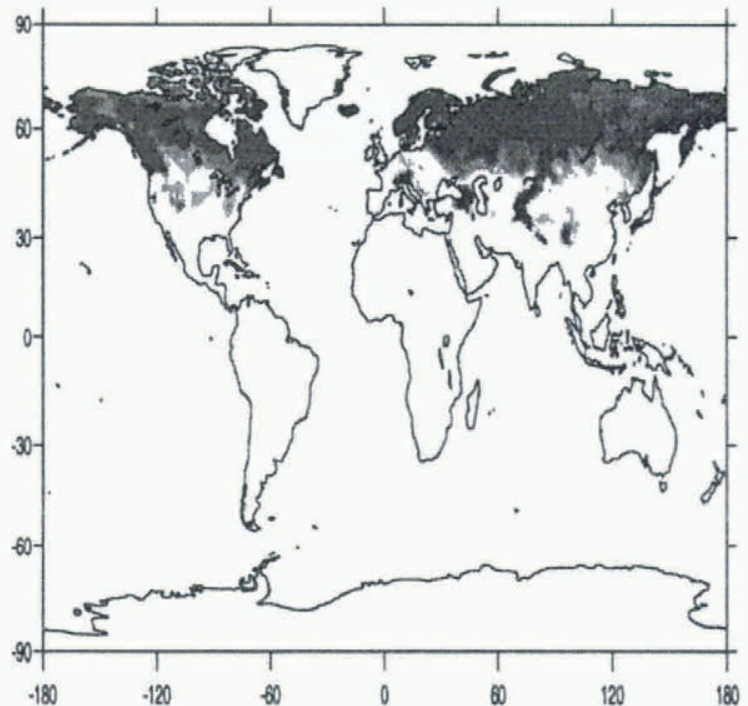

SNOW WATEREQUIV. (MM) - APR87 - SMMR

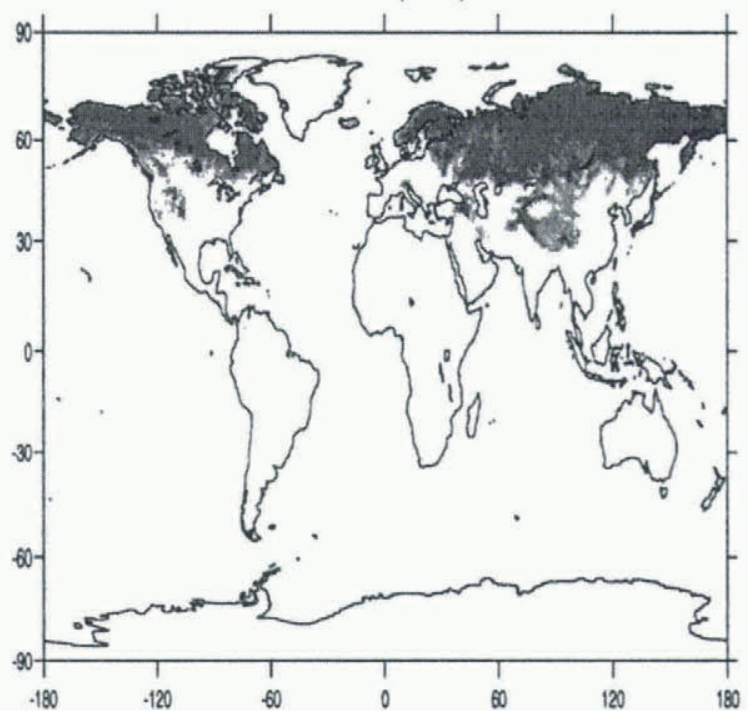

SNOW WATEREQUIV (MM) - APR - USAF

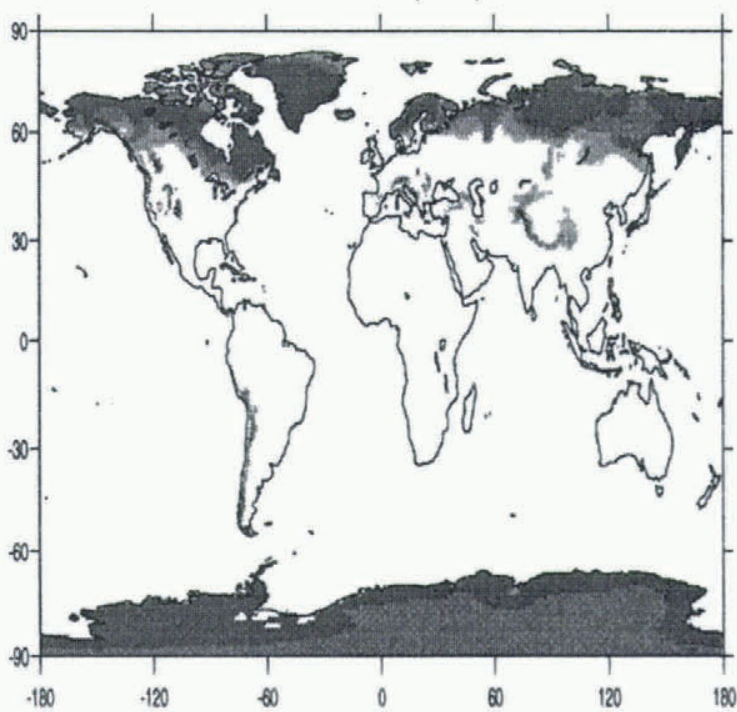

Fig. 2. Simulated, observed and climatological distribution of snow water equivalent in January and April 1987 (isolines are 1, 10, 50 and $100 \mathrm{~mm}$ ); for the simulated and observed data sets, the snow depth has not been plotted over ice sheets. 
In a previous study, it was shown that the use of the new snow hydrology in the ARPEGE climate model did not allow the correction of all the deficiencies observed in the simulation of the Northern Hemisphere snow cover (Douville and others, 1995b). The scheme improved the geographical distribution and the seasonal cycle of the snowpack, but its springtime removal was still slightly delayed. The analysis of the snow climatology produced by ISBA with the GSWP forcing should provide new data, to determine whether the excessive springtime snow cover found in the coupled simulation is due to the snow parameterization or to another defect in the ARPEGE climate model.

The ISBA land-surface scheme was first integrated for four annual cycles with the 1987 forcing until a reasonable periodicity was achieved on 1 January. The equilibrium appeared fairly quickly for snow depth, but was obtained later for soil moisture. A 2 year simulation was then performed using the 1987 and 1988 forcing. A surface air-temperature criterion of $2{ }^{\circ} \mathrm{C}$ has been used to distinguish between liquid and solid precipitation.

The produced snow fields were then compared to the US Air Force (USAF) climatology, based on terrestrial measurements, and to two satellite datasets: the NOAA weekly snow cover and the Nimbus-7 SMMR monthly snow depth. The global distribution of snow depth simulated by ISBA in January and April 1987 is not in a reasonable agreement with the SMMR dataset (Fig. 2). The snow lines are similar but the snow depths are sometimes quite different, the ISBA values being closer to the USAF climatology, at least in January. This seems to confirm that the passive-microwave dataset is not very reliable, especially over vegetated areas. It is still a challenge to monitor snow depth on a global scale.

The seasonal cycle of the simulated snow-cover extent was computed by using a $6 \mathrm{~mm}$ threshold of snow water equivalent to define the ISBA snow line, consistent with the NOAA visible observations (Fig. 3). The maximum and minimum snow-cover areas are well estimated, both for the Eurasian and North American continents. The timing of snow accumulation and melting is also realistic. However, there is a significant delay in the springtime snowmelt simulated in 1988: the simulation seems to underestimate inter-annual variability between 1987 and 1988.

In a fully interactive experiment, any snow-depth anomaly may be reinforced by a positive feedback between snowfall and snow cover. During the boreal spring, a slight underestimation of the melting rate may therefore lead to a significant overestimation of the Northern Hemisphere snow cover. No delay in the snow-cover removal was noticed in the local stand-alone tests. In these tests, a conductive heat flux from the soil was introduced in the surface-energy budget by setting the soil-surface temperature to $0^{\circ} \mathrm{C}$ under deep snow. This flux is not considered in the global simulation, which may explain the delay in the Northern Hemisphere snow-cover retreat. This emphasizes a shortcoming of the ISBA land-surface scheme, which does not compute a separate prognostic temperature for the snowpack.

\section{GONCLUSIONS AND OUTLOOKS}

The one-layer snow model included in the ISBA land-surface scheme seems to capture the main physical mechanisms governing the snow pack evolution. However, some improvements could be investigated, such as the retention and re-

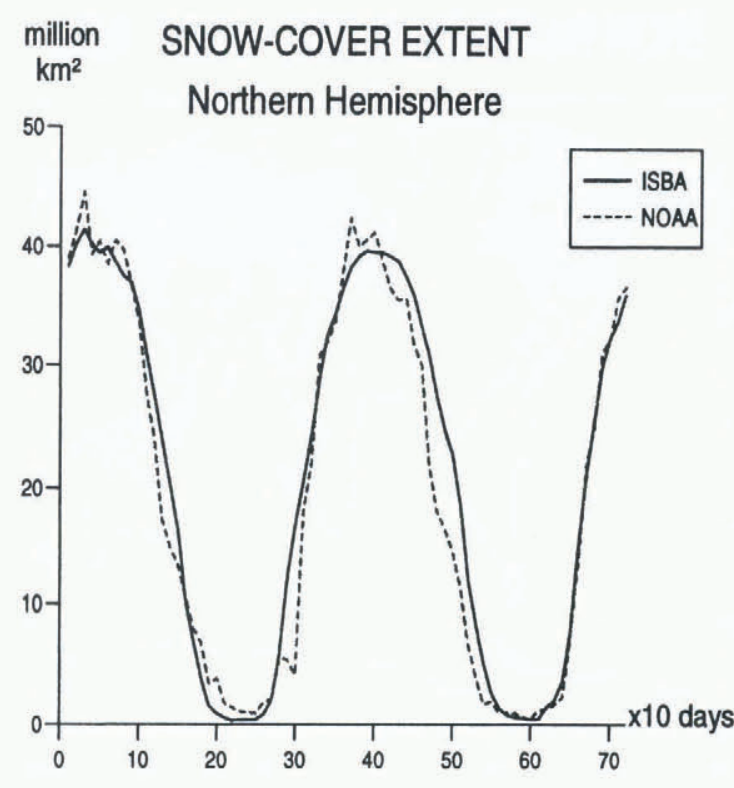

\section{million
$\mathrm{km}^{2}$ SNOW-COVER EXTENT Eurasia}
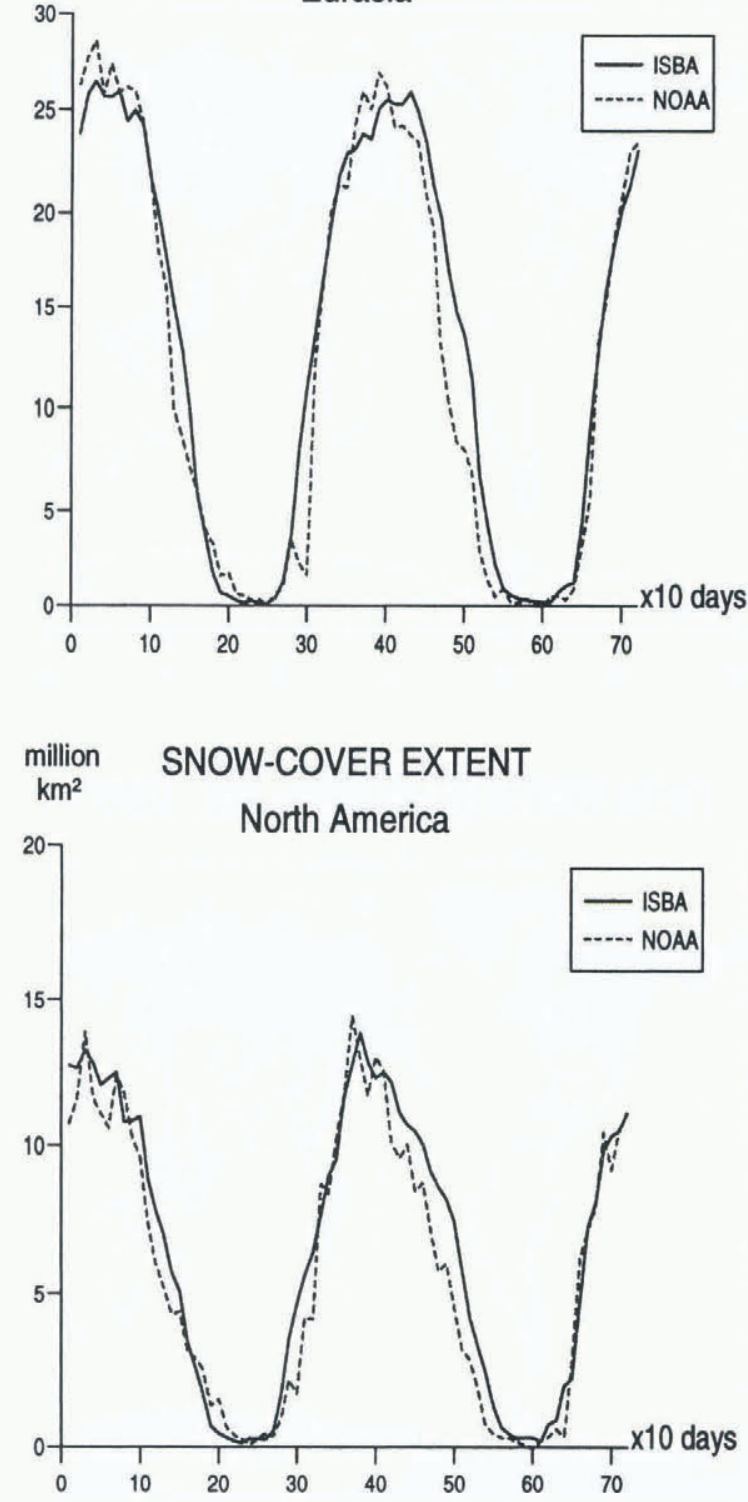

Fig. 3. Simulated and observed snow-cover evolution in 1987 and 1988 for the whole Northern Hemisphere, [Eurasia and North America]. 
freezing of liquid water within the snowpack. Preliminary tests were conducted by adding a prognostic equation for the liquid-water content in the snow, showing the importance of the percolation process. Slight improvements were obtained in the timing of the runoff from the snowpack. Further improvements will require a multi-layer snow mod$\mathrm{el}$, or at least an additional energy budget for the entiresnow layer. The single-surface energy budget computed in ISBA is the main obstacle for a more accurate estimation of snowmelt.

The ARPEGE climate model tends to overestimate the springtime snow cover. This common bias is often attributed to inaccuracies in modeling precipitation and temperature fields. However, defects in the snow parameterization might also be responsible for such behaviour. Further efforts to develop algorithms for estimating snow mass from satellites, and to validate the ability of GCMs to represent the seasonal snow cover, are still needed. A high degree of confidence in the models' predictions is necessary in order to study climate variability, both in high latitudes and the tropics (Douville and Royer, 1996).

\section{REFERENCES}

Dirmeyer, P. A. 1995. Problems in initializing soil wetness. Bull. Am. Meteorol. Soc., 76 (1), 2234-2240.

Douville, H. and J. -F. Royer. 1996. Sensitivity of the Asian summer monsoon to an anomalous Eurasian snow cover' within the Météo-France GCM. Climate Dyn., 12, 441-448.

Douville, H., J. F. Royer and J. F. Mahfouf. 1995a. A new snow parameterization for the Météo-France climate model. Part I. Validation in standalone experiments. Climate Dyn., 12 1), 21-35.

Douville, H., J. F. Royer and J. F. Mahfouf. 1995b. A new snow parameterization for the Météo-France climate model. Part II. Validation in a 3-D GCM experiment. Climate Dyn., 12 1),37-52.

Foster, J. L. and 9 athers. 1996. Snow cover and snow mass intercomparisons of general circulation model and remotely sensed datasets. J. Climate, $92,409-426$.

Noilhan, J. and S. Planton. 1989. A simple parameterization of land surface processes for meteorological models. Mon. Weather Rez., 117, 536-549. 